\title{
Erratum to: Ethnicity and bone: a South African perspective
}

\author{
Lisa K. Micklesfield • Shane A. Norris • \\ John M. Pettifor
}

Published online: 6 September 2011

(C) The Japanese Society for Bone and Mineral Research and Springer 2011

Erratum to: J Bone Miner Metab (2011) 29:257-267

DOI 10.1007/s00774-011-0269-5

In Table 2, all occurrences of "diaphysis" should read "metaphysis" and all occurrences of "metaphysis" should read "diaphysis".

The online version of the original article can be found under doi:10.1007/s00774-011-0269-5.

L. K. Micklesfield $(\bowtie) \cdot$ S. A. Norris · J. M. Pettifor

Developmental Pathways for Health Research Unit,

Department of Paediatrics, Faculty of Health Sciences,

University of the Witwatersrand, 7 York Rd, Parktown,

Johannesburg 2193, South Africa

e-mail: lisa.micklesfield@uct.ac.za

L. K. Micklesfield

UCT/MRC Research Unit for Exercise Science and Sports

Medicine, Department of Human Biology,

UCT School of Health Sciences, University of Cape Town,

Cape Town, South Africa 